\title{
Determinants of quality of life among patients attending monk healers and primary healthcare centers in Thailand
}

\author{
Karl Peltzer ${ }^{1,2}$, Supa Pengpid ${ }^{1,3}$
}

\author{
AFFILIATION \\ 1 Department of Research Administration and Development, University \\ of Limpopo, Polokwane, South Africa \\ 2 Department of Psychology, College of Medical and Health Sciences, Asia \\ University, Taichung, Taiwan \\ 3 ASEAN Institute for Health Development, Mahidol University, Nakhon \\ Pathom, Thailand
}

\section{CORRESPONDENCE TO}

Karl Peltzer. Department of Research Administration and Development, University of Limpopo, Turfloop Campus, Old Admin Block, Sovenga,
Polokwane, 0727, South Africa. E-mail: kfpeltzer@gmail.com ORCID ID: https://orcid.org/0000-0002-5980-0876

\section{KEYWORDS}

monk healer, primary care, quality of life, physical, psychological, environmental, social, Thailand

Received: 11 May 2021

Revised: 27 September 2021

Accepted: 24 November 2021

\begin{abstract}
INTRODUCTION The study aimed to assess the levels of Quality of Life (QoL) and to identify the associated factors in users of two different health services (monk healers and health centers) in Thailand.

METHODS In a cross-sectional design, 1251 patients were systematically (consecutively) recruited from three monk healers and three health centers and were assessed with questions on sociodemographic and clinical information, and QoL. Qol was measured using the World Health Organization Quality of Life (WHOQol)-8, for four QoL subdomains: psychological, physical, social and environmental.

RESULTS The overall QoL mean of 68.9 was significantly higher in primary care attendees than in monk healer attenders (mean of 66.6) $(\mathrm{p}<0.01)$. The social QoL domain had the highest scores, 72.5 and 72.1, in attendees of primary care and monk healers, respectively, followed by physical with 69.6 and 69.4, psychological with 66.1 and 62.9, and environmental with 67.3 and 62.2. In adjusted linear
\end{abstract}

regression analyses in the monk setting, higher education $(p<0.05)$, married $(p<0.01)$, and increasing age $(p<0.001)$ were associated with greater overall QoL, and having chronic conditions $(\mathrm{p}<0.001)$ was negatively associated with all QoL indicators. Furthermore, in the primary care setting, higher formal education $(p<0.05)$ was associated with overall QoL and psychological $(\mathrm{p}<0.05)$, physical $(\mathrm{p}<0.05)$, and environmental QoL $(\mathrm{p}<0.01)$. Having a smoking disorder was inversely associated with environmental QoL $(\mathrm{p}<0.05)$. Having multiple chronic conditions was negatively associated with the psychological $(\mathrm{p}<0.001)$ and environmental $(p<0.001)$ QoL subdomains as well as overall QoL $(p<0.05)$. CONCLUSIONS Sociodemographic characteristics such as younger age and lower education level, and clinical factors such as having chronic conditions, were associated with lower QoL in both monk and primary care treatment settings. Actions are indicated to improve QoL in both treatment settings in Thailand.

\section{INTRODUCTION}

The World Health Organization defines 'quality of life (QoL) as an individual's perception of their position in life within the context of the culture and value systems in which they live and in relation to their goals, expectations, standards and concerns ${ }^{1}$. QoL may include four different sub-domains, including psychological, physical, social and environmental ${ }^{2}$, and can be used to evaluate the health impacts of diseases ${ }^{1}$. Questions on QoL have become a needed component of public health surveillance and are considered as valid indicators of intervention outcomes ${ }^{3}$. In a systematic review, better or higher QoL has been found to reduce mortality risk ${ }^{4}$. Screening for QoL in general clinical practice, in addition to biological and health behavior measures, QoL measures may be able to predict mortality risk ${ }^{4}$. QoL is often assessed in relation to specific illness conditions, e.g. depressive disorders $^{5}$, chronic obstructive pulmonary disease ${ }^{6}$, or cancer ${ }^{7}$. However, fewer studies on QoL are conducted on the general primary care population, i.e. in a primary care clinic and a monk healer setting8. Understanding how 
sociodemographic and clinical patterns influence QoL is important to public health as it may influence healthy choices that people make or lifestyles. For example, does showing a patient - using a QoL measurement scale - the impact of smoking behaviors on their QoL influence smoking cessation? We have no information on how 'clinical patterns' across two service delivery models (primary care and monk healers) might affect QoL, which prompted the study.

Monk healers are traditional health practitioners that are widely distributed across all regions in Thailand ${ }^{9}$ providing various types of treatments, such as Thai traditional medicine and prayers at Buddhist temples ${ }^{10,11}$. For example, in a rural Buddhist temple in Thailand, herbal medicines, dietary treatment and meditation are provided for spiritual, mental and physical problems ${ }^{11}$; with a monk healer in central Thailand, treatments are given for various chronic diseases, such as pain conditions, diabetes, and cancer, and for skin, respiratory and digestive problems ${ }^{10}$; and in a Buddhist monastery in central Thailand, treatments are given for substance use disorders using religious, physical and herbal therapy ${ }^{12}$.

Several studies, as reviewed in Brazil ${ }^{8}$ and Nigeria ${ }^{13}$ found that social QoL had the largest contribution and environment QoL had the lowest contribution to overall QoL. In a study on QoL among older adults in a community in Brazil, lower QoL scores were identified in the environment and autonomy QoL subdomains ${ }^{14}$. In Reference Centers for the Elderly in Brazil, most older adults (63.4\%) had a good overall QoL score, while the lowest QoL was found in the environmental QoL subdomain ${ }^{15}$. In this case, a Reference Centre is a public facility that provides health promotion, legal and social services to older adults ${ }^{15}$.

In primary care patients, factors associated with lower overall QoL include younger age ${ }^{14}$, lack of schooling and income, a negative perception of health ${ }^{8,14}$, lower socioeconomic status ${ }^{13,16}$, lack of family support ${ }^{13}$, chronic conditions (such as diabetes, hypertension, depression, and musculoskeletal diseases $)^{8,13,15,17}$, and functional disability ${ }^{14}$.

In primary care patients, factors associated with lower psychological QoL include female sex, lower education, lower income, being a smoker, having a chronic disease, and poor self-rated health ${ }^{8}$. In primary care patients, factors associated with lower physical QoL include female $\operatorname{sex}^{18}$, lower education level, lower income, having no occupation, having a chronic disease, and poor self-rated health ${ }^{8}$.

In primary care patients, factors associated with lower social QoL include older age, not living with a partner, lower income, and being a smoker ${ }^{8}$. Likewise, factors associated with lower environmental QoL include older age, lower education level, and having own income ${ }^{8}$.

The aim of this investigation was to measure QoL and its correlates in users of two different types of health services (public primary care and monk health practitioners) in Thailand. QoL is an important outcome measure in primary care patients ${ }^{19}$. Therefore, an understanding of the QoL of attendees of two different health services (monk healers and primary care) in Thailand would be vital in improving primary care. To our knowledge, there is currently no knowledge on QoL among attendees of a monk healer setting. It is hypothesized that primary care attendees have higher QoL than monk healer attendees. This may have health policy implications, such as the existence of social determinants and $\mathrm{QoL}^{20}$, and integrated care interventions for improving patients with low $\mathrm{QoL}^{21}$. The aim of this investigation was to assess the levels of QoL and to identify the associated factors in users of two different health services (monk healers and health center) in Thailand.

\section{METHODS}

\section{Data collection and study population}

Using a cross-sectional study design, monk healer and primary care patients (aged $\geq 18$ years) were interviewed in Thai language by professional nurses from November 2018 to February 2019. Treatment centers (3 temples/ monk healers and 3 health centers who had at least 3 adult patients/day) located in Eastern and Central Thailand were selected by purposeful sampling. Patients attending the treatment centers were recruited by systematic or consecutive sampling. The study was approved by the Office of The Committee for Research Ethics (Social Sciences), Mahidol University (No.: 2017/055.1403) and written informed consent was obtained from participants.

\section{Study instrument}

\section{Sociodemographic data}

These consisted of education level, marital status, religion, employment status, age, sex, and economic status (extent of debt).

\section{Quality of Life (Qol)}

This was measured using the World Health Organization Quality of Life (WHOQol)-822. The 8-item scale includes: 'How would you rate your quality of life?' (Overall QOL), 'How satisfied are you with your health?' (overall QOL), 'Do you have enough energy for everyday life?' (physical health), 'How satisfied are you with your ability to perform your daily activities?' (physical health), 'How satisfied are you with yourself?' (psychological), 'How satisfied are you with your personal relationships?' (social relationships), 'Have you enough money to meet your needs?' (environmental), and 'How satisfied are you with the conditions of your living space?' (environmental) ${ }^{23}$. Results from the 2 -items subscales and the 8-items were summed to get subscale and overall WHOQoL scores, which were then transformed to a $0-100$ scale, with higher scores representing better $\mathrm{QoL}^{24}$. Cronbach alpha was 0.86 in this study.

\section{Chronic conditions}

These were assessed by self-reporting of 12 provider diagnosed conditions, including hypertension, diabetes, asthma, heart attack or stroke, high blood cholesterol, 
emphysema/asthma, sore joints, e.g. arthritis, gout, osteoporosis, cancer or a malignancy of any kind, migraine headaches, ulcer (a stomach, duodenal or peptic ulcer), fatigue disorder, and sleeping problems.

The Ultrarapid Alcohol, Smoking, and Substance Involvement Screening Test (ASSIST-Lite), which has been validated in Thailand, was sourced to measure smoking tobacco and alcohol use disorders ${ }^{25}$. The internal consistency of the ASSIST-Lite in this study had a Cronbach alpha of 0.90 .

\section{Statistical analysis}

The sample and QoL characteristics were described by using frequencies, percentages, means, and standard deviations. Pearson chi-squared tests and parametric tests were utilized for testing differences in proportions. Linear regression analyses were used to estimate the predictors of each QoL domain for patients of monk healers and health centers separately. The internal consistency of the scales used was assessed by using reliability analysis. The data analyses were conducted with IBMSPSS for Windows, version 25 (Chicago, IL, USA).

\section{RESULTS}

In all, 1251 patients of both treatment settings participated in the study, while the non-response rate was $3 \%$. The average age of participants of primary care attendees was significantly higher than among monk healer attendees $(\mathrm{p}<0.01)$, and the educational level $(\mathrm{p}<0.01)$ and prevalence of substance use disorders $(\mathrm{p}<0.01)$ were significantly higher in monk healer than health center attendees. Further study sample characteristics are shown in Table 1. The overall quality of life had a mean score of 68.9, significantly higher in primary care attenders than in monk healer attenders (mean: 66.6) $(\mathrm{p}<0.01)$. Among the four QoL subdomains social had the highest scores, 72.5 and 72.1 in attendees of primary care and monk healers, respectively, followed by physical with 69.6 and 69.4, psychological with 66.1 and 62.9, and environmental with 67.3 and 62.2 (Table 1).

\section{Associations with QoL in attenders of monk healers}

In the final multiple linear regression model, increasing age $(\mathrm{p}<0.001)$ was positively associated with psychological, social, and environmental QoL as well as overall QoL. Sex was not significantly associated with any QoL measure. Better education was associated with psychological $(\mathrm{p}<0.05)$, physical $(\mathrm{p}<0.05)$, and environmental QoL $(\mathrm{p}<0.001)$ as well as overall QoL $(p<0.05)$. Being married or cohabiting was associated with physical $(\mathrm{p}<0.05)$, social $(\mathrm{p}<0.01)$, and environmental QoL $(\mathrm{p}<0.01)$ as well as overall QoL $(\mathrm{p}<0.01)$. High debt was positively associated with environmental QoL $(p<0.05)$ and being employed was associated with

Table 1. Descriptive characteristics of the sample and quality of life by healthcare setting, Thailand 2019 (N=1251)

\begin{tabular}{|c|c|c|c|c|}
\hline \multirow[t]{3}{*}{ Characteristics } & \multicolumn{2}{|c|}{ Monk healer ( $n=607)$} & \multicolumn{2}{|c|}{ Health center $(n=644)$} \\
\hline & \multirow[b]{2}{*}{$\%$} & \multirow{2}{*}{$\begin{array}{c}\text { Overall quality of life } \\
\text { Mean (SD) }\end{array}$} & \multirow[b]{2}{*}{$\%$} & \multirow{2}{*}{$\begin{array}{c}\text { Overall quality of life } \\
\text { Mean (SD) }\end{array}$} \\
\hline & & & & \\
\hline All & & $66.6(16.2)$ & & $68.9(12.3)^{* *}$ \\
\hline \multicolumn{5}{|l|}{ Age (years) } \\
\hline $18-39$ & 39.2 & $64.8(17.9)$ & 16.1 & $68.9(12.3)$ \\
\hline $40-54$ & 39.2 & $67.7(14.7)$ & 33.2 & $70.3(11.8)$ \\
\hline $55-93$ & 30.3 & $65.2(17.0)$ & $50.7^{* * *}$ & $65.3(11.9)^{* *}$ \\
\hline \multicolumn{5}{|l|}{ Sex } \\
\hline Female & 75.5 & $66.5(16.5)$ & 72.7 & $68.6(12.6)$ \\
\hline Male & 24.5 & $64.8(16.4)$ & 27.3 & $70.5(12.3)$ \\
\hline \multicolumn{5}{|l|}{ Education level } \\
\hline Primary or less & 38.5 & $65.1(14.3)$ & 64.6 & $67.5(12.3)$ \\
\hline Secondary & 31.7 & $65.8(18.3)$ & 26.6 & $71.1(12.9)$ \\
\hline Post-secondary & 29.8 & $67.9(16.9)$ & $8.8^{* * *}$ & $73.7(11.6)^{* * *}$ \\
\hline \multicolumn{5}{|l|}{ Marital status } \\
\hline Single/divorced/widowed & 41.7 & $63.4(17.2)$ & 28.9 & $68.8(12.7)$ \\
\hline Married/cohabiting & 58.3 & $68.1(15.5)^{* * *}$ & $77.1^{* * *}$ & $69.1(12.5)$ \\
\hline \multicolumn{5}{|l|}{ Employment status } \\
\hline No & 32.0 & $62.8(17.1)$ & 27.9 & $65.5(15.2)$ \\
\hline Yes & 68.0 & $67.4(15.9)^{* * *}$ & 72.1 & $70.5(11.2)^{* * *}$ \\
\hline
\end{tabular}


Table 1. Continued

\begin{tabular}{|c|c|c|c|c|}
\hline \multirow[t]{3}{*}{ Characteristics } & \multicolumn{2}{|c|}{ Monk healer $(n=607)$} & \multicolumn{2}{|c|}{ Health center $(n=644)$} \\
\hline & \multirow[b]{2}{*}{$\%$} & Overall quality of life & \multirow[b]{2}{*}{$\%$} & \multirow{2}{*}{$\begin{array}{c}\text { Overall quality of life } \\
\text { Mean (SD) }\end{array}$} \\
\hline & & Mean (SD) & & \\
\hline \multicolumn{5}{|l|}{ In debt } \\
\hline No/little & 75.1 & $66.9(15.9)$ & 76.5 & $69.2(11.8)$ \\
\hline High & 24.9 & $65.7(17.2)$ & 23.5 & $67.9(13.7)$ \\
\hline \multicolumn{5}{|c|}{ Smoking disorder } \\
\hline No & 92.4 & $66.8(16.5)$ & 97.5 & $69.3(12.1)$ \\
\hline Yes & 7.6 & $60.6(17.2)^{*}$ & $2.5^{* * *}$ & $62.5(14.0)^{*}$ \\
\hline \multicolumn{5}{|c|}{ Alcohol use disorder } \\
\hline No & 90.0 & $66.6(16.7)$ & 95.7 & $69.0(12.1)$ \\
\hline Yes & 10.0 & $63.5(14.4)$ & $4.3^{* * *}$ & $69.2(16.2)$ \\
\hline \multicolumn{5}{|c|}{ Chronic diseases } \\
\hline 0 & 40.7 & $70.6(13.6)$ & 43.5 & $71.3(16.5)$ \\
\hline $1-2$ & 35.5 & $66.8(16.2)$ & 34.9 & $66.8(13.3)$ \\
\hline$\geq 3$ & 23.8 & $60.1(18.2)^{* * *}$ & 21.6 & $68.0(18.9)^{* * *}$ \\
\hline
\end{tabular}

SD: standard deviation. ${ }^{*} \mathrm{p}<0.05 ;{ }^{* *} \mathrm{p}<0.01 ;{ }^{* * *} \mathrm{p}<0.001$.

higher psychological QoL ( $\mathrm{p}<0.01)$. Having a smoking and/ or alcohol use disorder was not significantly associated with any QoL measures. Having chronic diseases was inversely associated with all QoL indicators $(\mathrm{p}<0.001)$ (Table 2).

\section{Associations with QoL in attenders of primary care}

In the final multiple linear regression model, increasing age was associated with environmental QoL $(\mathrm{p}<0.001)$, and being male increased the odds of better psychological QoL $(p<0.05)$. Higher formal education was associated with psychological $(\mathrm{p}<0.05)$, physical $(\mathrm{p}<0.05)$, and environmental $(\mathrm{p}<0.001)$ as well as overall QoL $(\mathrm{p}<0.05)$. Being married or cohabiting was negatively associated with social QoL $(\mathrm{p}<0.01)$. Having employment was positively associated with all QoL indicators. Having high debt was negatively associated with social QoL $(\mathrm{p}<0.05)$ and positively associated with environmental QoL $(\mathrm{p}<0.05)$. Having a smoking disorder was inversely associated with environmental QoL $(\mathrm{p}<0.05)$. Having multiple chronic conditions was inversely associated with overall QoL $(\mathrm{p}<0.05)$, psychological $(\mathrm{p}<0.001)$ and environmental QoL (0.001) (Table 3).

Table 2. Linear regression between social and clinical indicators with quality of life (QoL) domains in the monk healer setting, Thailand $2019(\mathrm{~N}=607)$

\begin{tabular}{|c|c|c|c|c|c|}
\hline \multirow[t]{3}{*}{ Variable } & \multicolumn{4}{|c|}{ Subdomains of QoL } & \multirow[t]{2}{*}{ Overall QoL } \\
\hline & Psychological & Physical & Social & Environmental & \\
\hline & ACoef $(95 \% \mathrm{CI})$ & ACoef $(95 \% \mathrm{CI})$ & ACoef $(95 \% \mathrm{CI})$ & ACoef $(95 \% \mathrm{CI})$ & ACoef $(95 \% \mathrm{CI})$ \\
\hline Age & $0.25(0.09-0.41)^{* *}$ & $0.14(-0.03-0.32)$ & $0.22(0.07-0.38)^{* *}$ & $0.33(0.19-0.48)^{* * *}$ & $0.24(0.11-0.37)^{* * *}$ \\
\hline \multicolumn{6}{|l|}{ Sex } \\
\hline \multicolumn{6}{|l|}{ Female (Ref.) } \\
\hline Male & $-0.69(-5.66-4.30)$ & $-3.52(-9.02-1.99)$ & $0.16(-4.69-5.01)$ & $-1.64(-6.14-2.85)$ & $-1.43(-5.55-2.69)$ \\
\hline \multicolumn{6}{|l|}{ Education level } \\
\hline \multicolumn{6}{|l|}{$\begin{array}{l}\text { Primary or less } \\
\text { (Ref.) }\end{array}$} \\
\hline Secondary & $5.57(0.76-10.38)^{*}$ & $6.76(1.44-12.08)^{*}$ & $2.36(-2.33-0.05)$ & $1.78(-2.56-6.12)$ & $2.01(0.10-8.07)^{*}$ \\
\hline Post-secondary & $6.03(1.15-10.91)^{*}$ & $3.20(-2.19-8.60)$ & $2.35(-2.41-0.06)$ & $8.49(4.09-12.90)^{* * *}$ & $2.44(0.98-9.06)^{*}$ \\
\hline
\end{tabular}


Table 2. Continued

\begin{tabular}{|c|c|c|c|c|c|}
\hline \multirow[t]{3}{*}{ Variable } & \multicolumn{4}{|c|}{ Subdomains of QoL } & \multirow[t]{2}{*}{ Overall QoL } \\
\hline & Psychological & \begin{tabular}{|l|} 
Physical \\
\end{tabular} & Social & Environmental & \\
\hline & ACoef $(95 \% \mathrm{CI})$ & ACoef $(95 \% \mathrm{CI})$ & ACoef $(95 \% \mathrm{CI})$ & ACoef $(95 \% \mathrm{CI})$ & ACoef $(95 \% \mathrm{CI})$ \\
\hline \multicolumn{6}{|c|}{ Marital status } \\
\hline \multicolumn{6}{|c|}{$\begin{array}{l}\text { Single/divorced/ } \\
\text { widowed (Ref.) }\end{array}$} \\
\hline $\begin{array}{l}\text { Married/ } \\
\text { cohabiting }\end{array}$ & $3.57(-0.28-7.42)$ & $4.46(0.21-8.72)^{*}$ & $5.82(2.08-0.15)^{* *}$ & $4.62(1.15-8.09)^{* *}$ & $4.64(1.45-7.82)^{* *}$ \\
\hline \multicolumn{6}{|c|}{$\begin{array}{l}\text { Employment } \\
\text { status }\end{array}$} \\
\hline \multicolumn{6}{|c|}{ No (Ref.) } \\
\hline Yes & $5.36(1.32-9.59)^{* *}$ & $1.66(-2.91-6.23)$ & $2.52(-1.50-6.55)$ & $1.28(-2.45-5.01)$ & $2.70(-0.73-6.12)$ \\
\hline \multicolumn{6}{|l|}{ In debt } \\
\hline \multicolumn{6}{|c|}{ No/little (Ref.) } \\
\hline High & $3.96(-0.12-8.04)$ & $-1.90(-6.43-2.62)$ & $0.53(-3.45-0.01)$ & $4.34(0.66-8.03)^{*}$ & $1.68(-1.71-5.06)$ \\
\hline \multicolumn{6}{|l|}{$\begin{array}{l}\text { Smoking } \\
\text { disorder }\end{array}$} \\
\hline \multicolumn{6}{|l|}{ No (Ref.) } \\
\hline Yes & $-4.28(-12.22-2.92)$ & $-0.04(-8.42-8.35)$ & $-5.76(-13.13-1.61)$ & $-4.05(-10.88--2.78)$ & $-3.73(-10.01-2.55)$ \\
\hline \multicolumn{6}{|c|}{$\begin{array}{l}\text { Alcohol use } \\
\text { disorder }\end{array}$} \\
\hline \multicolumn{6}{|c|}{ No (Ref.) } \\
\hline Yes & $-1.09(-8.72-5.79)$ & $2.11(-5.92-10.15)$ & $2.83(-4.24-9.90)$ & $-2.36(-8.91-4.19)$ & $0.20(-5.82-6.21)$ \\
\hline \multicolumn{6}{|l|}{$\begin{array}{l}\text { Chronic } \\
\text { diseases }\end{array}$} \\
\hline \multicolumn{6}{|l|}{0 (Ref.) } \\
\hline $1-2$ & $-4.28(-8.45--0.10)^{*}$ & $-5.94(-10.55--1.33)^{*}$ & $-5.79(-9.86--1.73)^{* *}$ & $-4.41(-8.18--0.64)^{*}$ & $-5.09(-8.54--1.63)^{* *}$ \\
\hline$\geq 3$ & $-12.95(-17.62--8.28)^{* * *}$ & $-13.27(-18.43--8.10)^{* * *}$ & $-11.03(-15.58-6.48)^{* * *}$ & $-9.58(-13.79--5.36)^{* * *}$ & $-11.68(-15.55--7.82)^{* * *}$ \\
\hline
\end{tabular}

Table 3. Linear regression between social and clinical indicators with quality of life (QoL) domains in the primary care setting, Thailand $2019(\mathrm{~N}=644)$

\begin{tabular}{|c|c|c|c|c|c|}
\hline \multirow[t]{3}{*}{ Variable } & \multicolumn{4}{|c|}{ Subdomains of QoL } & \multirow[t]{2}{*}{ Overall QoL } \\
\hline & Psychological & Physical & Social & Environmental & \\
\hline & ACoef $(95 \% \mathrm{CI})$ & ACoef $(95 \% \mathrm{CI})$ & ACoef $(95 \% \mathrm{CI})$ & ACoef $(95 \% \mathrm{CI})$ & ACoef $(95 \% \mathrm{CI})$ \\
\hline Age & $0.03(-0.09-0.15)$ & $0.00(-0.12-0.12)$ & $-0.02(-0.13-0.09)$ & $0.14(0.02-0.26)^{*}$ & $0.03(-0.07-0.13)$ \\
\hline \multicolumn{6}{|l|}{ Sex } \\
\hline \multicolumn{6}{|l|}{ Female (Ref.) } \\
\hline Male & $3.44(0.37-6.52)^{*}$ & $1.45(-1.60-4.50)$ & $1.83(-1.00-4.67)$ & $1.71(-1.33-4.76)$ & $2.22(-0.28-4.71)$ \\
\hline \multicolumn{6}{|l|}{ Education level } \\
\hline \multicolumn{6}{|l|}{$\begin{array}{l}\text { Primary or less } \\
\text { (Ref.) }\end{array}$} \\
\hline Secondary & $3.25(-0.32-6.81)$ & $5.15(-0.96-6.12)$ & $1.64(-1.65-4.93)$ & $6.57(-0.85-6.23)$ & $2.39(-0.51-5.29)$ \\
\hline Post-secondary & $5.07(0.07-10.07)^{*}$ & $4.63(0.20-10.11)^{*}$ & $3.95(-0.66-8.57)$ & $6.44(1.62-11.52)^{* *}$ & $5.00(0.96-9.05)^{*}$ \\
\hline
\end{tabular}


Table 3. Continued

\begin{tabular}{|c|c|c|c|c|c|}
\hline \multirow[t]{3}{*}{ Variable } & \multicolumn{4}{|c|}{ Subdomains of QoL } & \multirow[t]{2}{*}{ Overall QoL } \\
\hline & Psychological & Physical & Social & Environmental & \\
\hline & ACoef $(95 \% \mathrm{CI})$ & ACoef $(95 \% \mathrm{CI})$ & ACoef $(95 \% \mathrm{CI})$ & ACoef $(95 \% \mathrm{CI})$ & ACoef $(95 \% \mathrm{CI})$ \\
\hline \multicolumn{6}{|l|}{ Marital status } \\
\hline \multicolumn{6}{|l|}{$\begin{array}{l}\text { Single/divorced/ } \\
\text { widowed (Ref.) }\end{array}$} \\
\hline $\begin{array}{l}\text { Married/ } \\
\text { cohabiting }\end{array}$ & $-0.02(-3.33-3.28)$ & $-0.79(-4.06-2.49)$ & $-3.40(-6.45--0.35)^{*}$ & $-0.65(-3.91-2.61)$ & $-1.17(-3.83-1.50)$ \\
\hline $\begin{array}{l}\text { Employment } \\
\text { status }\end{array}$ & & & & & \\
\hline
\end{tabular}

No (Ref.)
\begin{tabular}{llllll} 
Yes & $3.95(0.48-7.42)^{*}$ & $4.63(1.20-8.07)^{* *}$ & $3.89(0.69-7.08)^{*}$ & $6.44(2.99-9.89)^{* * *}$ & $4.61(1.79-7.43)^{* * *}$ \\
In debt & & & & & \\
\hline $\begin{array}{l}\text { No/little (Ref.) } \\
\text { High }\end{array}$ & $-1.46(-4.60-1.68)$ & $-1.34(-4.44-1.77)$ & $-3.60(-6.49--0.70)^{*}$ & $3.74(0.62-6.86)^{*}$ & $-0.45(-2.99-2.10)$ \\
$\begin{array}{l}\text { Smoking } \\
\text { disorder }\end{array}$ & & & & & \\
\hline
\end{tabular}

No (Ref.)

$\begin{array}{llllll}\text { Yes } & -8.66(-17.92-0.59) & -7.95(-17.11-1.22) & -3.12(-11.66-5.42) & -12.17(-21.72--2.62)^{*} & -7.18(-14.98-0.61) \\ \begin{array}{l}\text { Alcohol use } \\ \text { disorder }\end{array} & & & & & \\ \begin{array}{l}\text { No (Ref.) } \\ \text { Yes }\end{array} & 1.17(-5.70-8.03) & -3.74(-10.55-3.05) & -4.89(-11.22-1.44) & -2.21(-4.60-9.02) & -1.58(-7.14-3.98) \\ \begin{array}{l}\text { Chronic } \\ \text { diseases }\end{array} & & & & & -3.34(-6.00-2.04) \\ 0 \text { (Ref.) } & -3.63(-2.17--0.35)^{*} & -2.51(-5.76-0.74) & 0.07(-2.95-3.10) & -7.24(-10.50- & -3.99)^{* * *} \\ 1-2 & -5.58(-17.62--1.73)^{* * *} & 0.42(-3.39-4.23) & 0.78(-2.77-4.33) & -7.39(-11.19--3.59)^{* * *} & -3.02(-6.13--0.08)^{*}\end{array}$

ACoef: adjusted coefficient. CI: confidence interval. ${ }^{*} \mathrm{p}<0.05 ;{ }^{* *} \mathrm{p}<0.01 ;{ }^{* * *} \mathrm{p}<0.001$

\section{DISCUSSION}

The study aimed at investigating QoL and its correlates in users of two different types of health services (public primary care and monk health practitioners) in Thailand. The average age of participants of primary care attendees was significantly higher than among monk healer attendees and the educational level and prevalence of substance use disorders were significantly higher in monk healer than health center attendees. It is possible that similar to the utilization of complementary medicine ${ }^{26,27}$, young and middle-aged and educated people in Thailand are more attracted to monk healer than health center care. Moreover, several previous studies ${ }^{26,28}$ have also shown that the prevalence of mental, including substance use, problems was higher in a traditional healer or complementary medicine setting compared to a primary health care setting.
It is possible that the expected treatment efficacy for mental health and substance use disorder is, in particular for young and middle-aged and educated people in Thailand, lower in the primary care than monk healer setting, which may mean that efforts should be made for integrated management.

This first study in Thailand found that the overall QoL had a mean of 68.9 , significantly higher in primary care attenders than in monk healer attenders (mean: 66.6). QoL was probably a little higher in this study than in Reference Centers for the Elderly in Brazil (63.4\%) ${ }^{15}$. Consistent with previous studies ${ }^{8,13,15}$, this study found that social QoL was the highest and environmental QoL was the lowest. It is possible that environmental QoL was low, particularly in the monk healer setting, because the studied communities were located in areas of greater social vulnerability ${ }^{8}$. It may be important to promote investment to improve the living 
condition of individuals residing in vulnerable $\operatorname{areas}^{8}$. The Brazil study in basic health units ${ }^{8}$ was in various aspects similar to our study in the primary care setting, using the same QoL measures, and similar patient profile, e.g. the preponderance of female patients $(79.9 \%$ vs $72.7 \%$ in our study), primary education ( $64.7 \%$ vs $64.6 \%$ in our study), and having a chronic disease ( $64.4 \%$ vs $66.5 \%$ in our study). The finding that the lowest-rated QoL domain was the environmental domain which calls for attention to the social determinants of health via improved social protection and support, especially among vulnerable populations.

In agreement with previous studies $8,14,15,17$, this study found in both monk healer and primary care setting an association between increasing age, higher educational level, and better overall QoL, while having chronic conditions was inversely associated with overall QoL. It is possible that some domains of QoL (psychological, social and environmental) similarly increase with age, as found in the case of life satisfaction ${ }^{29}$ and subjective well-being ${ }^{30}$. Having a higher educational level and being employed may be related to greater awareness and practice of health promoting behaviors and prompt healthcare access, which can all lead to improvements in QoL and health ${ }^{31}$. Having chronic conditions is more likely to limit daily functioning and negatively affect physical and psychological $\mathrm{QoL}^{8,32}$. In the primary care setting, employment was associated with all QoL indicators. Similarly, having an occupation increased the odds for physical QoL among primary care patients in Brazil. ${ }^{8}$ There were no sex differences in subdomain and overall QoL, as previously observed in a study among general practice clinic patients in Nigeria ${ }^{13}$.

Having a smoking disorder in the primary care setting was inversely associated with environmental QoL, while in a previous study being a smoker ${ }^{8}$ was associated with poorer social and psychological QoL. In a previous review, smoking has been found negatively associated with QoL, increasing with the number of cigarettes smoked, while smoking cessation significantly increases $\mathrm{QoL}^{33}$. Being married or cohabiting was in the monk health setting associated with overall QoL, physical, social, and environmental QoL, while in the study in Brazil not living with a partner was negatively associated with social QoL ${ }^{8}$. Similarly, in a study among older adults in Myanmar, being married was positively associated with QoL; spouses may play a significant role in providing material and psychosocial support to older adults ${ }^{34}$. Not having a social network seems to affect negatively various domains of QoL, including social QoL. Findings of this study have relevant research and clinical implications for primary care in Thailand, such that they highlight the relevance of interventions to improve QoL in primary care users in a religious and primary care setting ${ }^{8}$. Specifically, it is recommended that QoL issues be integrated into the management in the religious care management, in particular among those with chronic conditions, those who are single, divorced or widowed, who are younger and those with less education. Furthermore, in primary care management QoL issues should be integrated in those who are not employed, have lower education level, and have chronic conditions.

\section{Limitations}

The study measures were only assessed by self-report, which has its limitations. Furthermore, due to the cross-sectional study design, the direction of the relationship between sociodemographic and clinical study variables and QoL cannot be established.

\section{CONCLUSIONS}

The study extends previous research on QoL and its subdomains in both monk healer and primary care settings in Thailand. Social QoL had the highest scores, followed by physical, psychological, and environmental QoL. Sociodemographic characteristics such as younger age and lower education level, and clinical factors such as having chronic conditions, were associated with lower QoL in both treatment settings. Actions are indicated to improve QoL in both public primary and monk healer care settings in Thailand by targeting to improve environmental, psychological and physical QoL.

\section{REFERENCES}

1. The WHOQOL Group. The World Health Organization Quality of Life assessment (WHOQOL): position paper from the World Health Organization. Soc Sci Med. 1995;41(10):14031409. doi:10.1016/0277-9536(95)00112-k

2. Risal A, Manandhar S, Manandhar K, Manandhar N, Kunwar D, Holen A. Quality of life and its predictors among aging people in urban and rural Nepal. Qual Life Res. 2020;29(12):3201-3212. doi:10.1007/s11136-020-02593-4

3. HRQOL Concepts: Why is quality of life of important? Centers for Disease Control and Prevention. Updated October 31, 2018. Accessed June 20, 2021. https://www.cdc.gov/hrqol/ concept.htm

4. Phyo AZZ, Freak-Poli R, Craig H, et al. Quality of life and mortality in the general population: a systematic review and meta-analysis. BMC Public Health. 2020;20(1):1596. doi:10.1186/s12889-020-09639-9

5. Riihimäki K, Sintonen H, Vuorilehto M, Jylhä P, Saarni S, Isometsä E. Health-related quality of life of primary care patients with depressive disorders. Eur Psychiatry. 2016;37:28-34. doi:10.1016/j.eurpsy.2016.04.008

6. Esquinas C, Ramon MA, Nuñez A, et al. Correlation between disease severity factors and EQ-5D utilities in chronic obstructive pulmonary disease. Qual Life Res. 2020;29(3):607-617. doi:10.1007/s11136-019-02340-4

7. Pongthavornkamol K, Lekdamrongkul P, Pinsuntorn $\mathrm{P}$, Molassiotis A. Physical Symptoms, Unmet Needs, and Quality of Life in Thai Cancer Survivors after the Completion of Primary Treatment. Asia Pac J Oncol Nurs. 2019;6(4):363371. doi:10.4103/apjon.apjon_26_19

8. Almeida-Brasil CC, Silveira MR, Silva KR, et al. Quality 
of life and associated characteristics: application of WHOQOL-BREF in the context of Primary Health Care. Qualidade de vida e características associadas: aplicação do WHOQOL-BREF no contexto da Atenção Primária à Saúde. Cien Saude Colet. 2017;22(5):1705-1716. doi:10.1590/1413-81232017225.20362015

9. Adthasit R, Kulsomboon S, Chantraket R, Suntananukan S, Jirasatienpong $\mathrm{P}$. The situation of knowledge management and research in the area of local wisdom in health care. In: Petrakard P, Chantraket R, eds. The report situations of Thai traditional medicine, indigenous medicine and alternative medicine 2005-2007. Mnat Films; 2007:12-22.

10. Chan-iam W, Yodmalee B, Nakornriab M. Thai Traditional Medicine at Wat Nong Ya Nang Buddhist, Uthai Thani Province. Journal of Food Health and Bioenvironmental Science. 2019;12(2):41-48. Accessed September 27, 2021. http://www.researchold.dusit.ac.th/new/upload/ file/6b020c4a3cc62ec63cf0a789b8ad3448.pdf

11. Kaewla W, Wiwanitkit V. Local primary health care by local religious center: A case study of a Mahayana Buddhist temple, Thailand. Ann Trop Med Public Health. 2015;8(5):226. doi:10.4103/1755-6783.159850

12. Jilek-Aall L, Jilek WG. Buddhist Temple Treatment of Narcotic Addiction and Neurotic-Psychosomatic Disorders in Thailand. In: Pichot, Berner P, Wolf R, Thau K, eds. Psychiatry The state of the art: History of Psychiatry, National Schools, Education, and Transcultural Psychiatry. Vol 8. Springer; 1985:673-677. doi:10.1007/978-1-4757-1853-9_107

13. Fakoya 00, Abioye-Kuteyi EA, Bello IS, Oyegbade 00, Olowookere SA, Ezeoma IT. Determinants of Quality of Life of Elderly Patients Attending a General Practice Clinic in Southwest Nigeria. Int Q Community Health Educ. 2018;39(1):3-7. doi:10.1177/0272684X18781781

14. de Paiva MHP, Pegorari MS, Nascimento JS, da Silva Santos Á. Factors associated with quality of life among the elderly in the community of the southern triangle macro-region, Minas Gerais, Brazil. Fatores associados à qualidade de vida de idosos comunitários da macrorregião do Triângulo do Sul, Minas Gerais, Brasil. Cien Saude Colet. 2016;21(11):33473356. doi:10.1590/1413-812320152111.14822015

15. Miranda LCV, Soares SM, Silva PAB. Quality of life and associated factors in elderly people at a Reference Center. Qualidade de vida e fatores associados em idosos de um Centro de Referência à Pessoa Idosa. Cien Saude Colet. 2016;21(11):3533-3544. doi:10.1590/1413-812320152111.21352015

16. Morgan UOM, Etukumana EA, Abasiubong F. Sociodemographic Factors Affecting the Quality of Life of Elderly Persons Attending the General Outpatient Clinics of a Tertiary Hospital, South-South Nigeria. Niger Med J. 2017;58(4):138-142. doi:10.4103/nmj.NMJ_124_17

17. Ediriweera de Silva RE, Perera MSA. Quality of Life in Older Adults Attending a University Family Practice Centre in Sri Lanka. J Frailty Aging. 2018;7(2):134-137. doi:10.14283/jfa.2018.8

18. Muhwezi WW, Okello ES, Turiho AK. Gender-based profiling of Quality of Life (QOL) of primary health care (PHC) attendees in central Uganda: a cross sectional analysis. Afr Health Sci. 2010;10(4):374-385. Accessed September 27, 2021. https://www.ncbi.nlm.nih.gov/pmc/articles/ PMC3052806/pdf/AFHS1004-0374.pdf

19. Fayers PM, Machin D. Quality of Life: The Assessment, Analysis and Reporting of Patient-reported Outcomes. 3rd ed. John Wiley \& Sons; 2015.

20. Kivits J, Erpelding ML, Guillemin F. Social determinants of health-related quality of life. Rev Epidemiol Sante Publique. 2013;61(Suppl 3):S189-S194. doi:10.1016/j.respe.2013.06.001

21. Flanagan S, Damery S, Combes G. The effectiveness of integrated care interventions in improving patient quality of life (QoL) for patients with chronic conditions. An overview of the systematic review evidence. Health Qual Life Outcomes. 2017;15:188. doi:10.1186/s12955-017-0765-y

22. Schmidt S, Mühlan H, Power M. The EUROHIS-QOL 8-item index: psychometric results of a cross-cultural field study. Eur J Public Health. 2006;16(4):420-428. doi:10.1093/eurpub/cki155

23. da Rocha NS, Power MJ, Bushnell DM, Fleck MP. The EUROHIS-QOL 8-Item Index: Comparative Psychometric Properties to Its Parent WHOQOL-BREF. Value Health. 2012;15(3):449-457. doi:10.1016/j.jval.2011.11.035

24. Ha NT, Duy HT, Le NH, Khanal V, Moorin R. Quality of life among people living with hypertension in a rural Vietnam community. BMC Public Health. 2014;14:833. doi:10.1186/1471-2458-14-833

25. Ali R, Meena S, Eastwood B, Richards I, Marsden J. Ultrarapid screening for substance-use disorders: The Alcohol, Smoking and Substance Involvement Screening Test (ASSISTLite). Drug Alcohol Depend. 2013;132(1-2):352-361. doi:10.1016/j.drugalcdep.2013.03.001

26. Krug K, Kraus KI, Herrmann K, Joos S. Complementary and alternative medicine (CAM) as part of primary health care in Germany-comparison of patients consulting general practitioners and CAM practitioners: a cross-sectional study. BMC Complement Altern Med. 2016;16(1):409. doi:10.1186/s12906-016-1402-8

27. Peltzer K, Pengpid S, Puckpinyo A, Yi S, Anh le V. The utilization of traditional, complementary and alternative medicine for non-communicable diseases and mental disorders in health care patients in Cambodia, Thailand and Vietnam. BMC Complement Altern Med. 2016;16:92. doi:10.1186/s12906-016-1078-0

28. Ngoma MC, Prince M, Mann A. Common mental disorders among those attending primary health clinics and traditional healers in urban Tanzania. Br J Psychiatry. 2003;183(4):349355. doi:10.1192/bjp.183.4.349

29. Gana K, Bailly N, Saada Y, Joulain M, Alaphilippe D. Does Life Satisfaction Change in Old Age: Results From an 8-Year Longitudinal Study. J Gerontol B Psychol Sci Soc Sci. 2013;68(4):540-552. doi:10.1093/geronb/gbs093

30. Jebb AT, Morrison M, Tay L, Diener E. Subjective Well- 
Being Around the World: Trends and Predictors Across the Life Span. Psychol Sci. 2020;31(3):293-305. doi:10.1177/0956797619898826

31. Minh HV, Ng N, Byass P, Wall S. Patterns of subjective quality of life among older adults in rural Vietnam and Indonesia. Geriatr Gerontol Int. 2012;12(3):397-404. doi:10.1111/j.1447-0594.2011.00777.x

32. Pengpid S, Peltzer K. The Impact of Chronic Diseases on the Quality of Life of Primary Care Patients in Cambodia, Myanmar and Vietnam. Iran J Public Health. 2018;47(9):1308-1316. Accessed September 27, 2021. https://www.ncbi.nlm.nih.gov/pmc/articles/PMC6174032/ pdf/IJPH-47-1308.pdf

33. Goldenberg M, Danovitch I, IsHak WW. Quality of Life and Smoking. Am J Addict. 2014;23(6):540-562. doi:10.1111/j.1521-0391.2014.12148.x

34. Zin PE, Saw YM, Saw TN, et al. Assessment of quality of life among elderly in urban and peri-urban areas, Yangon Region, Myanmar. PLoS One. 2020;15(10):e0241211. doi:10.1371/journal.pone.0241211

\section{CONFLICTS OF INTEREST}

The authors have completed and submitted the ICMJE Form for Disclosure of Potential Conflicts of Interest and none was reported.

FUNDING

There was no source of funding for this research.

ETHICAL APPROVAL AND INFORMED CONSENT

Ethical approval was obtained from the Office of The Committee for Research Ethics (Social Sciences), Mahidol University (No.:
2017/055.1403). Written informed consent was obtained from the participants.

\section{DATA AVAILABILITY}

The data supporting this research are available from the authors on reasonable request.

\section{PROVENANCE AND PEER REVIEW}

Not commissioned; externally peer reviewed. 